\title{
Editorial: Northern Lights: Reflections on Canadian Gerontological Research
}

The occasion of the first meeting ir. Canada of the International Association of Gerontology (IAG) provides the Canadian Journal on Aging with a unique opportunity to review the state of the fields of gerontology and geriatrics in our country and to place that review in an international context. In this introduction to this special supplement of the Canadian Journal on Aging, we briefly overview the demographic context of aging in Canada; highlight selected features of gerontological and geriatric research in Canada in recent years, and describe several recent initiatives; and we outline the structure and focus of this volume.

\section{Demographic Contexts of Population Aging in Canada}

Among Canada's population of just over 30 million people, 3.7 million (approximately $12 \%$ of the population) are over the age of 65 . This figure is projected to rise to 5 million (14\% of the population) by 2011 (Moore \& Rosenberg, 1997). Presently, Canada is second only to Japan in current life expectancy at birth: 76 years for men in Japan and 75 years for men in Canada; 83 years for women in Japan, 81 years for women in Canada (McPherson, 1998). This figure varies across the country, however, with individuals living in large urban areas living one year longer on average than those in smaller cities or in rural areas (Dumas \& Bélanger, 1997). Among men and women of Canada's First Nations, life expectancy is seven years less than the overall Canadian average (FPT, 1999). At age 65, life expectancy is 16 years for men and 20 years for women; at age 80 , men can expect just over seven more years of life, and women just over nine (McPherson, 1998). While it is estimated that approximately 7 per cent of the population aged 65 and over lives in some form of long-term care institution (Statistics Canada, 1999), approximately 35 per cent of those aged 85 years and older are resident in long-term care. These figures, however, vary significantly across Canada.

Canada has a three-tiered retirement income system, which includes government-sponsored programs, employer sponsored plans, and individual savings and investments. Canada is known worldwide for its national health insurance program, which provides coverage for physician and hospital care (McPherson, 1998). Medical, drugs and nursing costs in long-term care settings are fully covered, while means-tested contributions to housing costs are the rule. However, recent reforms to health care in Canada (discussed elsewhere in this volume) have reduced the confidence

Canadian Journal on Aging / La Revue canadienne du vieillissement / Vol. 20 suppl. 1 2001, i-xu 
of Canadians in the adequacy of our medically-based model of health care delivery to meet needs.

\section{Canadian Gerontological and Geriatric Research in Review}

The Canadian Journal on Aging recently reached the milestone of 20 years of publication. The Journal covers the full spectrum of gerontological enquiry, from the biological aspects of aging, to educational gerontology, health sciences, psychology, social sciences, and social policy and practice in relation to aging and elderly persons. Several decade reviews and commentaries have examined trends in research, education, and funding for gerontology and geriatrics in Canada over this period (Béland, 1991, 1997; Martin-Matthews, 2000, 2001). These reviews indicate that the past two decades have seen significant change in the climate of gerontological research in Canada. A decade of unprecedented growth in the 1980s, a period which saw the establishment of a number of now internationally. renowned gerontology research centres across the country, was followed by a decade characterized by many funding and budgetary challenges and fewer research opportunities. As research resources from independent sources of funding, such as the Canadian federal Research Councils and other governmental agencies with peer reviewed granting mechanisms, were reduced throughout the 1990s and as the public policy agenda changed to include more demands for accountability and relevance, researchers increasingly had to turn to innovative solutions in order to address critical research questions. On the one hand, this led to more inter-institutional collaboration and multi-disciplinary research teams, increasing connections outside government for research funding, and new research partnerships; on the other hand, a decade of funding cuts left the Canadian research community with quite inadequate research infrastructure.

However, several recent national initiatives suggest renewed opportunities for gerontological and geriatric research in Canada. Prime among these is the creation, by the federal government, in June 2000 of the Canadian Institutes of Health Research (CIHR), and the establishment of an Institute of Healthy Aging. With Réjean Hébert of the Universite de Sherbrooke, Québec, recently appointed as the Institute's first Scientific Director, the Institute of Healthy Aging ${ }^{1}$ will provide something Canadian researchers in aging have not previously had: "a national focal point to synthesize ... research efforts [in aging] and act as a catalyst for ... [aging] research" (Chappell et al., 1999).

The CIHR itself is based on a substantially broadened definition of health (beyond "medical") research, and includes in its mandate not only biomedical and clinical research but also health systems and services research and population health research. It is anticipated that the CIHR will significantly enhance the funding resources available to researchers 
in serontology and geriatrics in Canada. The creation of an Institute dedicated specifically to research on aging was the result of active involvement and input by the Canadian gerontological and geriatric research communities. The Institute will support research to promote healthy aging and to address causes, prevention, screening, diagnosis, treatment, support systems, and palliation for a wide range of conditions associated with aging. The diverse range of research topics potentially eligible for funding support by the CIHR and the inherent multi-disciplinarity of the mandate of the Institute of Healthy Aging reflect a vision of geriatric and gerontological research that has been central to the mission and focus of the Canadian Association on Gerontology since its founding 30 years ago.

Another significant initiative in Canada is the establishment, currently underway, of a number of Statistics Canada Research Data Centres across the country. Statistics Canada has, over the years, had extensive involvement in the creation of data sets that are, with increasing frequency, being developed in collaboration with and accessible to the gerontological and geriatric research communities in Canada. These include the General Social Surveys and successive waves of the National Population Health Surveys. Analyses of large national datasets, such as the National Population Health Surveys, are increasingly the basis of studies of such health issues as falls and injuries. The role of Statistics Canada in working co-operatively with the aging and health research communities in the future will be further enhanced by initiatives which promote research and training on issues (such as aging) that make full use of social statistics; facilitation of access to detailed micro-data; and which maximize the research and public policy interface.

This interface between research and public policy has long been an important element in Canadian research on aging, although its prominence is somewhat under-emphasized in the papers in this volume. This Journal has published position papers developed by the Canadian Association on Gerontology on pension policy, home care policy, and policies relating to seniors and prescription drugs. The Canadian research community has written numerous articles on the interface between research and policy (Gee, 1997); many of these provide critical and rhetorical political analyses. Entire supplemental issues of the Journal have been focussed on policy issues relating to care for older persons in Canada and on such policy-relevant, international comparisons as long-term care in five countries. ${ }^{2}$ Canada's federal government has played a prime role in facilitating these discussions, through the provision of funding to facilitate research, dialogue and workshops, and the subsequent publication of papers on such topics as bridging policy and research on aging ${ }^{3}$ and in setting an evidencebased policy agenda for seniors' independence. ${ }^{4} \mathrm{~A}$ federally-funded Project on Trends, a collaborative effort of the federal Policy Research Secretariat and the Social Sciences and Humanities Research Council (SSHRC) was recently designed as a new model for academics and government to collabo- 
rate on policy research and to facilitate the policy development process (Cheal, 2000).

\section{Canadian Gerontological and Geriatric Research in International Perspective}

In the eight years since the announcement of Canada's successful bid to host the 17th Congress of the International Association of Gerontology, members of the Board of the Canadian Association on Gerontology and the Editorial Board of the Canadian Journal on Aging well recognized the opportunity afforded by the Congress to showcase Canadian research in gerontology and geriatrics. From the outset, there was recognition of the potential importance of the Association's official journal as one of the vehicles of dissemination of Canada's research strengths in aging to the international community.

The guest editors of this volume, both former Editors-in-Chief of the Canadian Journal on Aging, invited several prominent Canadian researchers, whose research reflected the scholarly enquiries of various editorial sections within the Journal (health and biological sciences, social sciences, psychology, social policy and practice, and educational gerontology), to contribute a "review" article identifying the key research and policy issues currently relevant to their discipline(s) in Canada. Authors were asked to identify the key research questions and issues which have dominated their fields of enquiry in Canada, and to discuss these in relation to gaps in knowledge, research challenges, and priorities for future research.

Those invited to prepare manuscripts, which were all subsequently peer reviewed and revised, reflect the diversity of the Canadian gerontological and geriatric research community, and are acknowledged leaders in their research areas nationally and internationally. While space limitations precluded the involvement of a broader spectrum of prominent Canadian researchers in this volume (and there are many known to the international community), the researchers whose work is represented here each bring particular strengths to the analyses of Canadian research in gerontology and geriatrics in an international context.

Neena Chappell is a former Chair of the Research Committee on Aging of the International Sociological Association; in this issue, she and Margaret Penning of the University of Victoria overview Canadian gerontological research representative of the social sciences, with a primary focus on the sociology of aging.

Research trends in the psychology of aging are reviewed by Roger Dixon, the current President of the Adult Development and Aging Division of the American Psychological Association, and Anna-Lisa Cohen. They provide an overview of Canadian research and training initiatives across the broad spectrum of enquiry characteristic of the psychology of aging. 
Frédéric Lesemann was similarly invited to prepare a submission which would overview research issues related to social policy and practice and their relationship to aging in Canada. Lesemann, who has published international comparisons of home-based care, older persons, the family and the welfare state in Europe, the United States and Canada, provides an analysis of some of the current issues relevant to the policy development and research interface in Canada. He also presents an extensive contextual and historical interpretation of the diverse forces and circumstances which have shaped and defined Canadian gerontological research in recent decades.

The health sciences section of the Canadian Journal on Aging receives fully one-third of all submissions for publication in the Journal. Although research on biological aspects of aging is undertaken at several universities across the country (Riabowol, 1999), the Canadian Journal on Aging receives very few research submissions on biology and aging; therefore, this research area is also not well represented in this volume. However, because of the overall prominence of health sciences research in Canada, two submissions were invited: one in the broad area of health services and health policy, and the other focused on an overview of geriatric research. Robert Evans, Morris Barer and Clyde Hertzman of the University of British Columbia's Centre for Health Services and Policy Research are known internationally for their role in the creation of British Columbia's health-linked data base and for their ground-breaking research on the social determinants of health and on the socio-economic implications of health policy and reform of health services delivery nationwide.

Kenneth Rockwood and Colin Powell of Dalhousie University are internationally recognized leaders of Canadian geriatric research and have played prominent roles in the Canadian Study of Health and Aging. With their colleague Chris MacKnight, they review some of the most prominent works in the field of geriatrics in Canada. They show how medical care research issues are developed within and depend on each country's health care system.

The one division of the Canadian Association on Gerontology (CAG) not formally represented in this volume is Educational Gerontology. In 1989 an educational interest group was formed within the CAG; by 1990 more than 140 members had identified with this group, and in 1996 the group was approved as a division of the the CAG. As Sandy Macpherson (1997) notes in his overview of this nascent field in Canada, research in educational gerontology usually involves three components: research pertaining to the education of seniors themselves, the education of the general public about issues of individual and population aging, and the education of professionals and service providers. In Canada to date, the training and pedagogical functions of the division of educational gerontology have been noteworthy; a number of educational and training initiatives in gerontology and geriatrics in Canada are identified in several of the papers 
prepared for this volume. However, Canadian research initiatives in educational gerontology are comparatively few relative to other areas of gerontological enquiry.

Beyond showcasing the state of research on aging in Canada, the editors of this special issue also sought to give a uniquely "international" focus to the volume. Selected scholars were therefore invited to provide a short commentary on the Canadian paper in their areas of expertise, and, specifically, to place the issues in an international context. Authors were invited to compare and contrast the Canadian research foci and findings with related research in their area of the world (for example, the United States or Asia, or in an even broader international context, if they so wished). The initial intent was to include commentaries from researchers in all regions representative of the IAG, although this proved infeasible for reasons of space and time constraints. However, the regions of Europe, North America, and Asia are included among the international commentaries.

Canadian experiences of aging occur in the context of a rapid global pace of population aging. As several papers in this volume attest, policies, practices, training, and research on aging in Canada are strongly influenced by our powerful neighbour to the south, the United States. Several authors note these synergies and connections in their commentaries. Several commentaries, particularly those by European and francophone colleagues, acknowledge the cultural and linguistic diversity of Canada, and the challenges and opportunities related thereto. Other commentaries reflect the vigour of the debates within Canada as to the historic and present-day implications (for the research communities in gerontology and geriatrics) of Canada's two founding cultures and languages, French and English. And finally, in recognizing Vancouver as the host city for Canada's role in this World Congress, and its emergence as an important centre of population movement and commerce within the Pacific Rim, one commentary provides a comparative review of research and policy issues in Asia and in Canada.

These papers and commentaries well support the observation made by McCallum (1997) as Australia prepared for its own hosting of the IAG; namely, that "the forces of globalization are as powerful in research and practice in aging as they are in other aspects of late twentieth century life". The 17th Congress of the International Association of Gerontology in Vancouver provides an invaluable opportunity for dialogue and exchange as delegates from around the globe gather to discuss and disseminate research in gerontology and geriatrics - research to which many Canadian investigators have made significant contributions.

\section{Notes}

1 Information on the Canadian Institutes of Health Research and specifically on the Institute of Healthy Aging is available at http: \\www.cihr.ca. 
2 Produced in 1996, this issue of the Canadian Journal on Aging (Vol. 15, suppl. 1) provided international comparisons of long-term care policies and practices in Australia, the Netherlands, Norway, Canada, and the United States, and discussed the International Collaborative Effort on Measuring the Health and Health Care of the Aging.

3 A Special Joint Issue of the journals Canadian Public Policy-Analyse de Politiques (Volume XXIII, supplement) and the Canadian Journal on Aging (Vol. 16 suppl.) addressed this topic in 1997.

4 This topic was addressed in a supplement published by the $C J A$ (Vol. 19, suppl. 1) in 2000.

\section{References}

Béland, F. (1991). The Canadian Journal on Aging enters its tenth year. Canadian Journal on Aging, 10(1), 4-5.

Béland, F. (1997). Building Canadian gerontology: A springboard for international recognition? Canadian Journal on Aging, 16(1), 6-10.

Chappell, N.L., Joanette, Y., McDonald, L., Neysmith, S., Rockwood, K., Stones, M., \& Tuokko, H. (1999). Canadian Institutes of Health Research: The Canadian Insititute on Aging/Institut canadien de vieillissement (Concept of Operations). Victoria: Center on Aging, University of Victoria.

Cheal, D. (2000). Aging and demographic change. Canadian Public Policy-Analyse de Politiques (Special Supplement on the Trends Project), XXVI(Suppl.), S109-S122.

Dumas, J., \& Bélanger, A. (1997). Report on the demographic situation in Canada, 1996. Ottawa: Statistics Canada.

FPT. (1999). Rapport sur la santé des canadiens et des canadiennes. Préparé par le Comité consultatif fédéral provincial territorial sur la santé de la population, Canada.

Gee, E.M. (1997). Policy and research on aging: Connections and conundrums. Canadian Journal on Aging and Canadian Public Policy-Analyse de Politiques, Special Joint Issue, CJA Volume 16(Suppl.), i-viii.

Macpherson, A. (1997). Educational gerontology - a sleeping giant awakened. Canadian Journal on Aging, 16(4), 593-601.

Martin-Matthews, A. (2000). Canadian research on aging: Decade of maturation, time of change. Canadian Journal on Aging, 19(4), i-vii.

Martin-Matthews, A. (2001). A decade of gerontological research in Canada. Contemporary Gerontology, 7(2), 2-5.

McCallum, J. (1997). Australian gerontology and geriatric medicine in review. Australian Journal on Ageing, 16(3), 98.

McPherson, B.D. (1998). Aging as a social process (3rd ed.). Toronto: Harcourt Brace.

Moore, E., \& Rosenberg, M. (1997). Growing old in Canada: Demographic and geographic perspectives. Ottawa: Statistics Canada.

Riabowol, K. (1999). Biological aging research in Canada: Past, present and future. Canadian Journal on Aging, 18(1), i-vii.

Statistics Canada. (1999). A portrait of seniors in Canada, 3rd ed. Ottawa: Statistics Canada, Catalogue 89-XPE, pp. 46. 